Plant Tissue Cult. \& Biotech. 26(1): 123-130, 2016 (June)

$\overline{\mathrm{PTC} \& \mathrm{~B}}$

\title{
Development of Mutants in Sugarcane through Callus Culture
}

\author{
Kuasha Mahmud ${ }^{*}$, KM Nasiruddin ${ }^{1}$, MA Hossain and L Hassan ${ }^{2}$ \\ Biotechnology Division, Bangladesh Sugarcane Research Institute, Ishurdi-6620, \\ Bangladesh
}

Key words: Sugarcane, Callus, EMS, Mutants

\begin{abstract}
The effects of different concentrations $(0.0 \mathrm{M}, 0.01 \mathrm{M}, 0.02 \mathrm{M}$ and $0.03 \mathrm{M}$ for 24 hours treatment) of chemical mutagen like, ethyl methanesulfphonate (EMS) on callus derived from sugarcane var. Isd 37, Isd 39 and Isd 40 were investigated for in vitro plant regeneration. The highest number of shoots $(58.33 \%)$ was reduced over control of Isd 40 followed by Isd 37 (57.62\%) and Isd 39 (the lowest 56.06\%), respectively due to the use of EMS for treating calli. The regeneration of mutant plantlets was achieved from EMS $(0.01 \mathrm{M})$ treated calli obtained from leaf sheath explants on MS supplemented with 2, 4-D (3 mg/l) and 10\% coconut water. Most of the mutant plants were developed from Isd 37. The developed mutant plants showed variation in tiller number, internode, green leaf, millable cane and stalk colour from the source variety of Isd 37.
\end{abstract}

\section{Introduction}

The genus Saccharum contains three cultivated (Saccharum officinarum, S. sinensis and S. barbari) and two wild (Saccharum robustum and S. spontanium) species (Kochhar 1998). Sugarcane is globally the main source of raw material for the production of sugar. It is a principal cash crop in north western and south western low rainfall belt of the country and the main raw material for sugar and gur industries in Bangladesh. Although many countries are producers, only six of them account for $65 \%$ of the world's entire sugarcane production. Among these Brazil is the largest one (Viera 2002). It is very important to increase cane productivity without further area expansion to meet the future need of sugar and gur in Bangladesh. Sugarcane is a photo-tharmal sensitive crop and flowering takes place at 5 to $23^{\circ}$ latitude whereas Bangladesh is situated at $24.0160^{\circ} \mathrm{N}$ latitude and $89.8667^{\circ} \mathrm{E}$ longitude. Other conditions required for changing the

*Author for correspondence: <ahmudkuasha@gmail.com>. ${ }^{1}$ Department of Biotechnology, Bangladesh Agricultural University, Mymensingh, Bangladesh. ${ }^{2}$ Department of Genetics \& Plant Breeding, Bangladesh Agricultural University, Mymensingh, Bangladesh. 
vegetative to reproductive phase are temperature range 25 to $33^{\circ} \mathrm{C}$ for 70 days, humidity 70 to $80 \%$ for 70 days, day length 11.5 to 12.5 hrs for 70 days. The low cane and sugar yields are attributed to many factors in which drought, salinity, insect pests and diseases are major constraints (Nasir et al. 2000 and Khaliq et al. 2005). Production of large number of disease-free seedlings during the planting season is laborious and time consuming. Development of more efficient methods for large-scale production of pathogen free planting mateial would contribute significantly to the overall productivity of the sugar industry. Tissue culture techniques offer an opportunity to produce large scale of disease free planting material and are being used to supplement commercial sugarcane propagation in many countries including Brazil, the United States, India and Cuba (Lakshmanan et al. 2006). Both average cane yield ( $45 \mathrm{t} / \mathrm{ha}$ ) and recovery percentage of sugar (around 8.3 to 8.5) are fur below in Bangladesh as compared to those of the advanced sugarcane growing countries. Furthermore, it takes several years of painstaking labour to produce a pure line of sugarcane by selfing due to its high polyploidy and extreme heterozygosity (Narayana 1994). Somaclonal variation had produced desirable agronomic changes in the progeny for example eye spot resistant and increase in sugar yield in sugarcane (Evans et al. 1984). Callus masses from different explants were reported by many workers, namely, Laurens et al. (1987), Chen et al. (1998), Shaheen and Mirza et al. (1989). Use of different growth regulators was reported by Bhansali and Kishan (1982).

Many workers have reported organogenesis and differentiation of shoot from callus culture (Shaheen and Mirza 1989). In vitro regeneration of sugarcane has been reported by Barbara and Nickell (1969), Heinz and Mee (1969) and Barbara et al. (1977). Leaf tissue of modern hybrids of sugarcane clones is usually more responsive to tissue culture than those of traditional varieties or wild relatives (Chen et al. 1998, Taylor et al. 1997).

Many researchers compared the mutagenic efficiencies of different mutagens on different crops and their results seem to be entirely specific for particular species and even varieties. Ethyl methanesulfphonate (EMS) is a chemical mutagen and has been one of the most powerful mutagens used in crop plants. Hence tissue culture research using EMS with modern sugarcane varieties of Bangladesh deserves due attention. Conventional breeding method usually require 10 - 15 years to complete a section cycle for release of a variety and an important variety can be planted commercially several years later when enough seed canes are produced. Time required and continued contaminations by systemic diseases are also serious problem to multiply any elite genotype of sugarcane in the open field (Lal and Sing 1994).

Due to increased demand of sugar and gur for local consumption, sugarcane is being cultivated for long without adopting modern technologies. To get desirable traits and to meet the future requirement of sugar it is essential to develop some improved varieties through tissue culture method using mutagen 
such as EMS. Therefore, the present investigation was carried out to induce variation in local varities of sugarcane through the application of mutagens using in vitro techniques.

\section{Materials and Methods}

The experiment was conducted at the Biotechnology Laboratory, Bangladesh Sugarcane Research Institute (BSRI), Ishurdi, Pabna, Bangladesh during the period from September, 2010 to January, 2011 to investigate in vitro plant regeneration capability of BSRI released variety such as, Isd 37, Isd 39 and Isd 40. The leaf sheath explants collected from 8 - 10 months old field grown sugarcane from BSRI experimental field were used for this study.

The explants were kept in a beaker and treated with 3\% (w/v) Savlon for 5 - 6 minutes with constant shaking and washed thoroughly with distilled water for 3 - 4 minutes. The explants were then treated with $1 \% \mathrm{HgCl}_{2}$ and followed by washing 3 - 4 times with sterile distilled water. Explants (approximately $1 \mathrm{~cm} \times$ $0.5 \mathrm{~cm}$ ) were prepared in laminar air flow cabinet from sterilized leaf sheath segments. Besides, $\mathrm{pH}$ of the medium was adjusted to 5.7 and agar $(0.6 \%)$ was added in the medium. Media was sterilized by autoclaving at $1.2 \mathrm{Kg} \mathrm{cm}-2$ pressure at $121^{\circ} \mathrm{C}$ for 30 minutes. Cultures were incubated at $25 \pm 2^{\circ} \mathrm{C}$ and kept 16 hrs under fluorescent tube light. The experiment was laid out in Complete Randomized Design (CRD). There were three replications and ten test tubes of each treatment. The data were statistically analyzed following Factorial Completely Randomized Design (CRD).

MS with coconut water (10\%) containing $3 \mathrm{mg} / \mathrm{l}$ of 2,4-D was prepared for callus induction and treated with EMS (0, 0.01, 0.02, $0.03 \mathrm{M}$ for 24 hours). Treated calli were transferred to MS including 2,4-D and then transferred into shooting medium. Calli obtained from 2,4-D (3 mg/l) were treated with different concentrations of mutagen. Treated calli were aseptically transferred to fresh medium containing the BAP $(3 \mathrm{mg} / \mathrm{l})$ for proliferation and development of shoots. After inoculation of callus for 20 days on shooting medium, small green leaves began to emerge. Callus with tiny leaves were transferred to fresh medium containing the same concentration of BAP for further proliferation of shoots. Days required for shoot initiation were recorded from the beginning of shoot formation. Moreover, number of shoots per callus, length per shoot, shoot initiation percentage and also increased/decreased shoot (\%) for mutagen application were recorded following inoculation on shooting medium. After sufficient amount of shoot formation, the shoots were aseptically transferred onto fresh medium containing NAA $(5 \mathrm{mg} / \mathrm{l})$ for development of roots. Days required for root initiation, the number of roots per shoot, length of roots and increased/decreased number of root (\%) due to mutagen treated were recorded 
after inoculation of shoots in the rooting medium. Rooted plantlets were acclimated and transplanted to polybag and then to field, respectively.

\section{Results and Discussion}

Various responses were ovserved among the shoots and roots derived from EMS treated callus derived from the leaf seath explants from different varieties of sugarcane.The lowest numbers of days required for shoot and root initiation (7.83 and 6.25, respectively) were recorded from the variety Isd 37 while similar time (6.25 days) was also required for root initiation by Isd 40 and it was maximum (9.41 and 7.83 days, respectively) in Isd 39. On the other hand, both the varieties Isd 37 and Isd 40 produced significantly the maximum shoots per callus (4.25) while Isd 39 produced the maximum roots per shoot (3.91). Similarly, Isd 39 showed the minimum shoots per callus (3.00) while both the varieties Isd 37 and 40 produced similar (3.50) roots per shoot. No shoots and roots were produced in 0.02 and 0.03 M EMS. Among other treatments, without EMS required least time for shoot and root initiation (10.89 and 7.22 days, respectively) than 0.01 EMS (23.78 and 19.67 days, respectively). Similarly, medium without EMS showed significantly the highest number of shoots per callus (10.67) and roots per shoot (11.11) than 0.01 EMS (4.66 and 3.44, respectively). This finding is in agreement with the results of Gahukar et al. (2000) who reported that EMS affected the regeneration efficiency (RE) where RE significantly decreased in increasing EMS level. Significant variation was also found due to combined effect between varieties and EMS regarding shoots and root characters. There was no shoot and root formation on 0.02 and 0.03 in EMS. Among other treatment combinations, Isd 37 without EMS required the shortest time for shoot initiation (9.66 days) and Isd 40 in without EMS requiring least time for root initiation (6.66 days) while statistically similar least time for root initiation (7.00 days) was noted by the variety Isd 37 in without EMS. Both requiring days for shoot and root initiation had maximum (25.33 and 22.67 days, respectively) in Isd 39 by using 0.01 EMS. In the contrary, without EMS both Isd 40 and Isd 37 showed statistically similar maximum shoots per callus (12.00 and 11.67, respectively) while it was minimum shoots per callus (3.66) similar concentration of EMS of Isd 39. The variety Isd 39 in without EMS showed maximum roots per callus (11.67) followed by Isd 40 in similar EMS (11.00) whereas it was the minimum roots per shoot (3.00) in Isd 40 with 0.01 M EMS followed by Isd 37 in simialr EMS (3.33) (Table 1). In case of shoot and root initiation EMS treated callus showed variation with 2,4-D derived callus. It revealed that the requiring days were more for shoot and root initaition due to the use of EMS. Besides, number of shoots and roots were produced less due to the use of EMS. The maximum number of shoots $(58.33 \%)$ decreased over the control from the callus derived from Isd 40 variety, while Isd 39 yielded the 
Table 1. Effects of varieties and EMS concentrations on shoot and root characters at 30 days on shooting media and 20 days on rooting media after inoculation.

\begin{tabular}{|c|c|c|c|c|c|}
\hline \multicolumn{2}{|c|}{$\begin{array}{c}\text { Source varieties } \times \\
\text { EMS }(\mathrm{M} / \mathrm{l})\end{array}$} & \multirow{2}{*}{$\begin{array}{c}\begin{array}{c}\text { Days to shoot } \\
\text { initiation }\end{array} \\
9.66 \mathrm{f}\end{array}$} & \multirow{2}{*}{$\begin{array}{c}\begin{array}{c}\text { Number of } \\
\text { shoots per } \\
\text { callus }\end{array} \\
11.67 \mathrm{a}\end{array}$} & \multirow{2}{*}{$\begin{array}{c}\begin{array}{c}\text { Days to root } \\
\text { initiation }\end{array} \\
7.00 \mathrm{~d}\end{array}$} & \multirow{2}{*}{$\begin{array}{c}\begin{array}{c}\text { Number of } \\
\text { roots per shoot }\end{array} \\
10.67 \mathrm{~b}\end{array}$} \\
\hline Isd 37 & 0.00 & & & & \\
\hline & 0.01 & $21.67 \mathrm{c}$ & $5.33 c$ & $18.00 \mathrm{~b}$ & $3.33 \mathrm{~cd}$ \\
\hline & 0.02 & - & - & - & - \\
\hline & 0.03 & - & - & - & - \\
\hline \multirow[t]{4}{*}{ Isd 39} & 0.00 & $12-33 \mathrm{~d}$ & $8.33 \mathrm{~b}$ & $8.00 \mathrm{c}$ & $11.67 \mathrm{a}$ \\
\hline & 0.01 & $25.33 \mathrm{a}$ & $3.66 \mathrm{~d}$ & $22.67 \mathrm{a}$ & $4.00 \mathrm{c}$ \\
\hline & 0.02 & - & - & - & - \\
\hline & 0.03 & - & - & - & - \\
\hline \multirow[t]{4}{*}{ Isd 40} & 0.00 & $10.67 \mathrm{e}$ & $12.00 \mathrm{a}$ & $6.66 \mathrm{~d}$ & $11.00 \mathrm{ab}$ \\
\hline & 0.01 & $24.33 \mathrm{~b}$ & $5.00 \mathrm{c}$ & $18.33 \mathrm{~b}$ & $3.00 \mathrm{~d}$ \\
\hline & 0.02 & - & - & - & - \\
\hline & 0.03 & - & - & - & - \\
\hline $\operatorname{LSD}_{(0.05)}$ & & 0.689 & 0.732 & 0.843 & 0.689 \\
\hline CV (\%) & & 4.17 & 11.5 & 7.44 & 11.22 \\
\hline
\end{tabular}

In a column, figure having same letter(s) do not differ significantly by DMRT at the $5 \%$ level.

lowest $(56.06 \%)$ due to EMS treatment. The highest number of plantlets $(99.33 \%)$ were obtained from Isd 40 variety followed by Isd 37 (98.66\%) and also Isd 39 (the lowest $94.33 \%$ ), respectively without mutagen application (Table 2). On the other hand, the highest number of plantlets $(82 \%)$ was observed from Isd 40 , while the lowest (74\%) from Isd 39 due to mutagen treatment. Furthermore, the highest mortality $(5.66 \%)$ of plantlets was observed in Isd 39-followed by Isd 37 $(1.33 \%)$ and Isd $40(0.66 \%)$, respectively without mutagen treatment. On the contrary, the highest number of mortality (26\%) of plantlets was recorded in Isd 39 while the lowest (18\%) in EMS treated Isd 40.

Table 2. Hardening of plantlets of different varieties after 15 days.

\begin{tabular}{ccccc}
\hline $\begin{array}{c}\text { Source of } \\
\text { plantlets/ } \\
\text { variety }\end{array}$ & $\begin{array}{c}\text { \% of } \\
\text { survivability } \\
\text { (no EMS) }\end{array}$ & $\begin{array}{c}\text { \% of } \\
\text { survivability } \\
\text { in EMS }\end{array}$ & $\begin{array}{c}\text { \% of mortality } \\
\text { (without mutagen) }\end{array}$ & $\begin{array}{c}\text { \% of } \\
\text { mortality } \\
\text { (EMS) }\end{array}$ \\
\hline Isd 40 & $99.33 \mathrm{a}$ & $82.00 \mathrm{a}$ & $0.66 \mathrm{~b}$ & $14.67 \mathrm{~b}$ \\
Isd 39 & $94.33 \mathrm{~b}$ & $74.00 \mathrm{~b}$ & $5.66 \mathrm{a}$ & $26.00 \mathrm{a}$ \\
Isd 37 & $98.66 \mathrm{a}$ & $81.33 \mathrm{a}$ & $1.33 \mathrm{~b}$ & $18.67 \mathrm{~b}$ \\
LSD & 1.998 & 2.106 & 1.998 & 6.985 \\
$\mathrm{CV}(\%)$ & 1.03 & 1.33 & 9.13 & 7.68 \\
\hline
\end{tabular}

In a column, figure having same letter(s) do not differ significantly by DMRT at the $5 \%$ level. 
The highest number of survivability (20.33\%) of plantlets derived from callus treated by EMS was reduced over control from Isd 39 source variety followed by Isd $37(17.33 \%)$ which is similar to Isd 40 variety. Plantlets were planted in the earthen pots (Fig. 1). Sugarcane mutants such as CCM 37 1, CCM 37 2, CCM 37 3, CCM 374 and CCM 375 were developed from Isd 37 variety (Fig. 2).
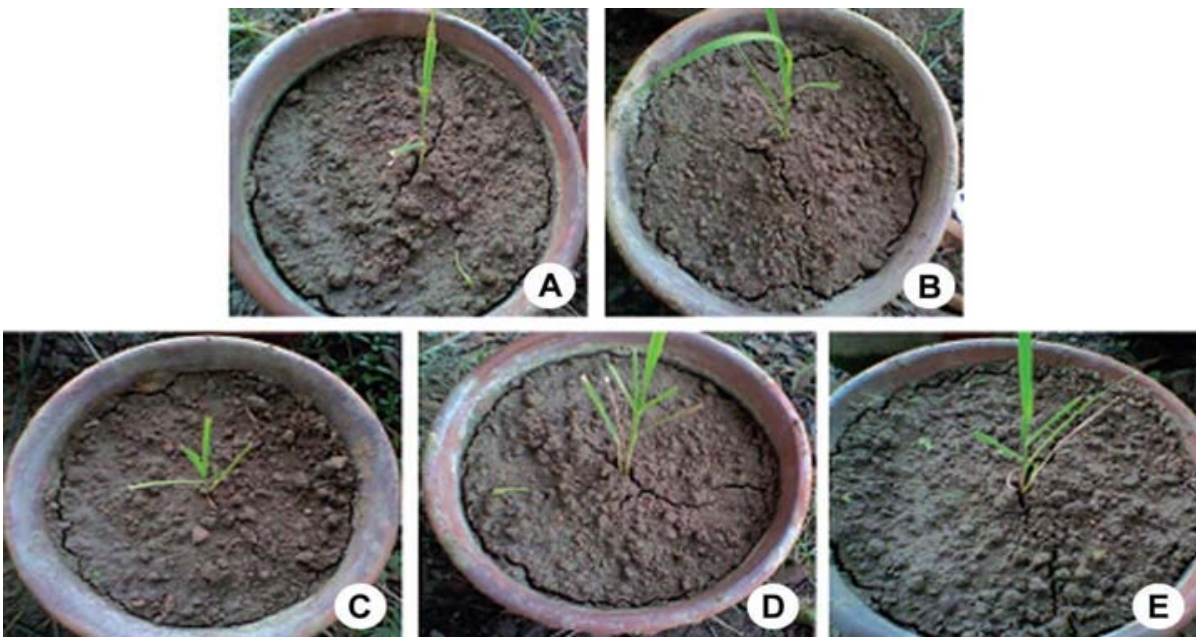

Fig. 1. Plantlets in earthen pots after 30 days of planting (A) CCM 37 1. (B) CCM 37 2. (C) CCM 37 3. (D) CCM 37 4. (E) CCM 375.
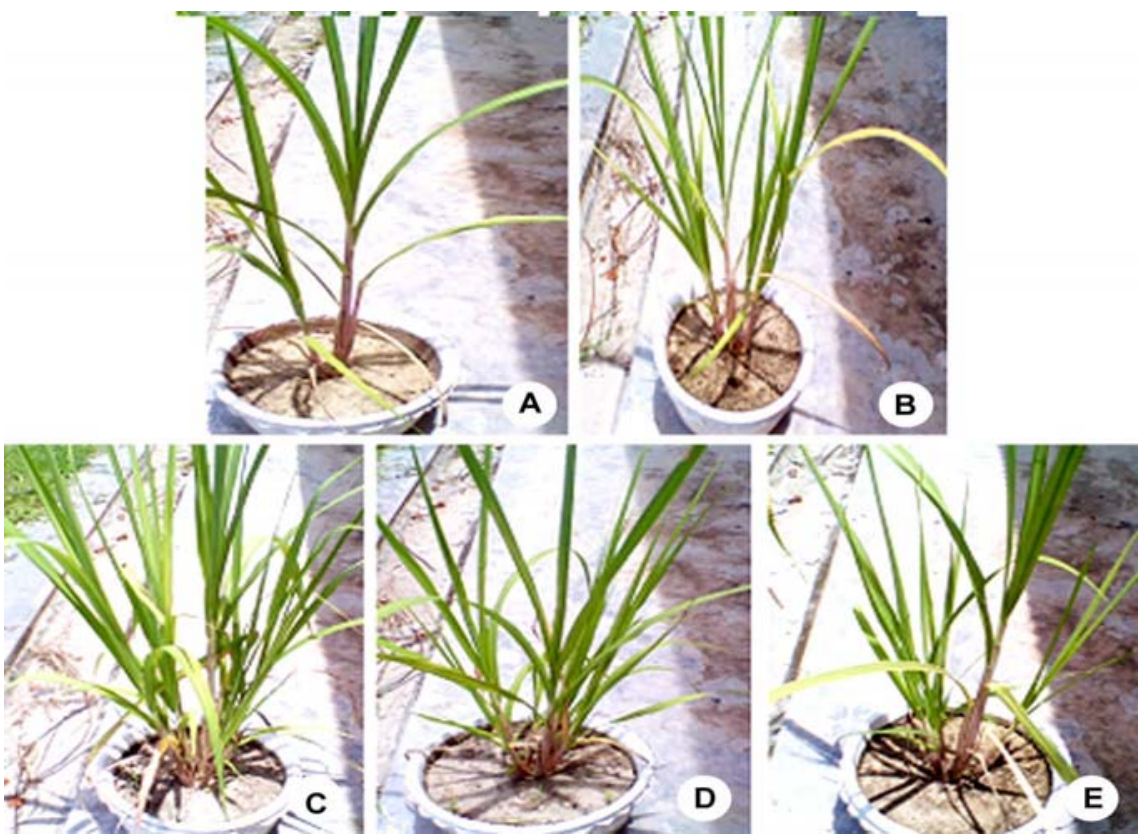

Fig. 2. Mutants in earthen pots after 5 months (A) CCM 37 1, mutant. (B) CCM 37 2. (C) CCM 37 3. (D) CCM 37 4. (E) CCM 375. 
Mutants produced different number of tillers, internodes, green leaves, millable cane and with change in other traits such as reddish color canestalk from yellowish green parent Isd 37. The highest number of green leaves (10) was obtained from mutants CCM 371 and CCM 37 4, while the lowest from mutant CCM 37 2. The maximum number of tillers per clump (10) was recorded in mutant CCM 375 followed by Isd 37 variety while the minimum (1) from mutant CCM 37 1. The highest number of millable cane (5) was observed in Isd 37, CCM 373 and CCM 374 . Besides, CCM 371 produced the highest (14) number of internodes per plant followed by CCM 375 (11). The lowest number of internodes (7) was recorded in CCM 373 mutant.

\section{References}

Barbara R and Nickell LG (1969) Nutrition and organ differentiationin tissue culture of sugarcane-a monocotyledon.Planta 89: 299-302.

Barbara RC, Zamora AB, MallionandLinga CK (1977) Sugarcane tissue culture research. Plant Physiol. 2: 1843-1863.

Bhansali RR, Kishan S (1982) Callus and shoot formation from leaf of sugarcane in tissue culture. Phytomorphology, pp. 167-170.

Chen WH, Davey MR, Power JB and Cocking EC (1998) Control and maintenance of plant regeneration in sugarcane callus culture. J. Expt. Bot. 39: 251-261.

Evans DA, Sharp WR and Medmi-Filho HP (1984) Somaclonal and gametoclonal variation. Amer. J. Bot. 71: 759-774.

Gahukar SJ andJambhale ND (2000) Callus induction and regeneration in Saccharum cultivars as influenced by mutagen treatments. J. Maharashtra Agril. Univ. 25(2): 219220.

Heinz DJ andMee GWP (1969) Plant differentiation from callus tissue of saccharum spp. Crop Sci. 9: 346-348.

Khaliq A, Ashfaq M, Akram W, Choi JK and Lee J (2005) Effect of plant factors, sugar contents and control methods on top borer (Scirpophaganivella F.) infestation in selected varieties of sugarcane. Entomological Res. 35: 153-160.

Kochhar SL (1998) Economic Botany in the tropics. Second Edition, Macmillan. India Ltd., pp. 1-476.

Lal N and Singh HN (1994) Rapid clonal multiplication of sugarcane through tissue culture.Plant Tissue Cult. 4(1): 1-7.

Lakshmanan P, Geijskes RJ, Wang L, Elliott A, Grof CPL, Berding N and Smith GR (2006) Development and hormonal regulation of direct shoot organogenesis and somatic embryogenesis in sugarcane (Saccharum spp. Interspecific hybrids) leaf culture. Plant Cell Rep. 25: 1007-1015.

Laurens AG and Martin FA (1987) Evaluation of in vitro propagated sugarcane hybrids for somaclonal variation. Crop Sci. 27: 793-796.

Narayna S (1994) Cereal and grass tissue culture.In. Plants Cell and Tissue Culture, Maheshwari, P. and Rangaawamy, N. S. (eds). Academic Press. pp. 173-322.

Nasir NM, Qureshi RH andAslam M (2000) Effect of salinity on emergence of sugarcane lines. Pakistan Sugar J. 15: 12-14. 
Shaheen MS andMirza MS (1989) In vitro production of plants from sugarcane tissue. J. Agric. Res. 26(6): 302-312.

Taylor PWJ (1997) Micropropagation of sugarcane (Saccharum spp. Hybrid). Biotech. Agricult. and Forestry 39: 256-268.

Viera (2002) Genetic stability of sugarcane plants derived from meristem culture. Genetic and Molecular Biol. 235(1): 91-96. 